Article

\title{
Chemical Constituents and Structural Characterization of Polysaccharides from Four Typical Bamboo Species Leaves
}

\author{
Cheng-Zhang Wang ${ }^{1,2,3,4, *}$, Hong-Yu Zhang ${ }^{1}$, Wen-Jun Li ${ }^{1}$ and Jian-Zhong Ye ${ }^{1}$ \\ 1 Institute of Chemical Industry of Forest Products, CAF, Nanjing 210042, China; \\ E-Mails: chemicalzhy@163.com (H.-Y.Z.); liwenjun611@163.com (W.-J.L.); \\ yejianzhong1984@163.com (J.-Z.Y.) \\ 2 National Engineering Laboratory for Biomass Chemical Utilization, Nanjing 210042, China \\ 3 Key Laboratory of Biomass Energy and Material, Nanjing 210042, China \\ 4 Institute of New Technology of Forestry, CAF, Beijing 100091, China \\ * Author to whom correspondence should be addressed; E-Mail: wangczlhs@sina.com; \\ Tel./Fax: +86-25-8548-2471.
}

Academic Editor: Derek J. McPhee

Received: 1 December 2014 / Accepted: 12 February 2015 / Published: 5 March 2015

\begin{abstract}
In order to find bamboo leaves with high contents of bioactive polysaccharides, 32 samples were chosen to analyze their polysaccharide content by GC and sulfuric acid-anthrone colorimetric assays. Purified polysaccharides (BLPS) were separated from the four varieties $P$. nigra (Lodd.) Munro (PN), P. vivax McClure (PV), Chimonobambusa quadrangularis (Fenzi) Makino (CQ), and P. bambussoides cv. Tanakae (PB) by ultrasound extraction, solution precipitation, ion exchange resin, DEAE-52 and Sephadex G-100 chromatography. BLPS structural characterization was accomplished by HPLC-GPC, Fourier transform infra-red spectroscopy (FTIR) and $\mathrm{NaIO}_{4}-\mathrm{HIO}_{4}$ oxidation reactions. The results showed that the total polysaccharides of the bamboo leaves in samples 1-32 ranged between 1.4\% and 5.4\%, Samples No. 29-No. 32 (PN, PV, CQ, and PB) contained 2-3 fold more polysaccharides than No. 1 No. 28 among the 32 different species, particularly the content of galactose was in a range of $21.5 \%-34.1 \%$ for these four typical bamboo species leaves, which was also more than 2-3 fold higher than in No. 1-No. 28. Sugar analysis indicated that PN-PBLPS-1, PV-PBLPS-1, CQ-PBLPS-1 and PB-PBLPS-1 from the four varieties were homogeneous polysaccharides with molecular weights of $2.04 \times 10^{4}, 1.15 \times 10^{4}, 8.75 \times 10^{4}$ and $1.48 \times 10^{4} \mathrm{Da}$, respectively. PB-PBLPS-1 was a mixture of $\alpha$-galactopyranose and $\beta$-D-glucopyranose linkages with
\end{abstract}


$\alpha-(1 \rightarrow 6)$ or $\beta-(1 \rightarrow 6)$ glycosidic bonds, while PN-PBLPS-1, PV-PBLPS-1, and CQ-PBLPS-1 had $\alpha$ galactopyranose linkages with $\alpha-(1 \rightarrow 6)$ glycosidic bonds.

Keywords: bamboo leaves; polysaccharides; HPLC-GPC; FTIR; $\mathrm{NaIO}_{4}-\mathrm{HIO}_{4}$

\section{Introduction}

Bamboo belongs to the Gramineae Bambusoideae subfamily and is one of the most valuable evergreen perennial plants in China and South-east Asia. China has been known as the "bamboo kingdom", and bamboo timber is a traditional forest product containing high cellulose, hemicellulose and lignin used as a construction material [1].

Generally hemicelluoses are a family of polysaccharides which contain a backbone of D-xylopyranosyl residues, linked together by $\beta$ - $(1 \rightarrow 4)$-glycosidic bonds [2], while the bioactive polysaccharides in bamboo are oligosaccharides of $\beta$-D-glucan and xyloglucan or $p$-coumaroyl arabinoxylan [3]. The investigation showed that bamboo shoot polysaccharides are composed of arabinoxylan $(1 \rightarrow 3,1 \rightarrow 4)-\beta$-D-glucan, xyloglucan and glucomannan [4], and other kinds of arabino-glucuronoxylans are also isolated from bamboo shoot with a linear $(1 \rightarrow 4)-\beta$-D-xylopranosyl backbone to which $\alpha$-L-arabinofuranose units or short chains of 4-O-methylglucuronic acid. However, these hemicellucosic polysaccharides have a average molecular weight $\left(\mathrm{M}_{\mathrm{r}}\right)$ range of $10 \times 10^{4}-40 \times 10^{4} \mathrm{Da}$, and this results in very weak physiological activity.

In order to get strongly bioactive polysaccharides with a average $\mathrm{M}_{\mathrm{r}}$ range of less than $10 \times 10^{4} \mathrm{Da}$, scientists often use chemical or biological ways to degradate macromolecular polysaccharides. This causes serious environmental pollution and results in high costs, therefore, it is very important to seek highly bioactive polysaccharides with low molecular weight from forestry resources or biomass residues. Apart from bioactive compounds like flavonoids, glycosides and polyphenols, bamboo leaves contain a large amount of active polysaccharides [5-7]. Extract of bamboo leaves (EBL) has been proved very safe and is used widely in China as an antioxidant in food additives [8]. The key bioactive compounds of EBL are polysaccharides and flavonoids, where particularly bamboo oligosaccharides play important functions $[9,10]$.

The polysaccharide of bamboo leaves (BLPS) is a kind of bioactive heteropolysaccharide with medium molecular mass. BLPS was first isolated from Japanese bamboo leaves of Sasa kurilensis and Sasamorpha chiisanensis [11]. The reported average molecular mass $\mathrm{M}_{\mathrm{r}}$ of the BLPS was determined to be in a range of $2 \times 10^{4}-3 \times 10^{4} \mathrm{Da}$, and this BLPS was proven to have good antitumor activity. Kato separated $\beta$-D-glucan and xyloglucan bioactive polysaccharides from bamboo shoots [12], while Suzuki also obtained from green bamboo shoots a bioactive hemicellulose polysaccharide with strong inhibition on $\mathrm{S}_{180}$ tumors [13]. Tang extracted and purified polysaccharides with an average molecular weight $\left(\mathrm{M}_{\mathrm{r}}\right)$ range of $10^{3}-10^{4} \mathrm{Da}$ from bamboo leaves of Phyllostachys heterocycla cv. pubescens, and it had very strong physiological activity [9]. The bioactive BLPS is composed of xylose, arabinose, glucose and galactose, as well as lesser amounts of mannose, rhamnose and uronic acids. In recent years, Ye investigated the total content and chemical constituents of polysaccharides from 17 kind species of bamboo leaves from the Nanjing region, Jiangsu Province. The total content of polysaccharides was 
between $1.9 \%-5.7 \%$ [14,15]. Lu found polysaccharide levels approaching $14.55 \%$ in bamboo leaves of Sinocalamus latiflorus McClure [16].

The composition and content of BLPS show very large changes for different varieties, growth place, harvest season, and growth ages. However, so far, there has been little investigation concerning the chemical composition and structural characterization of BLPS from different varieties in China with mono-sugar links, and their average $\mathrm{M}_{\mathrm{r}}$ and bioactivity.

In this paper, 32 varieties of bamboo leaves from Zhejiang Province in South-East China were chosen to investigate the content of polysaccharides obtained by ultrasound-assisted extraction. Phyllostachys nigra (PN), Phyllostachys vivax (PV), Chimonobambusa quadrangularis (Fenzi) Makino (CQ) and Phyllostachys bambusoides (PB) have been screened to investigate the structural characterization of the purified bamboo leaves polysaccharides (PBLPS) obtained after solution precipitation to remove proteins, ion exchange resin bleaching, and finally purification using DEAE-52 and Sephadex G-100 chromatography. This investigation is of significance to develop new healthcare foods or medicines from BLPS by using the processed bamboo residues.

\section{Results and Discussion}

\subsection{The Components and Content of Polysaccharides in Different Bamboo Leave Varieties}

Six kinds of standard monosaccharides were mixed, derivatized and checked by gas chromatography as seen in Figure 1.

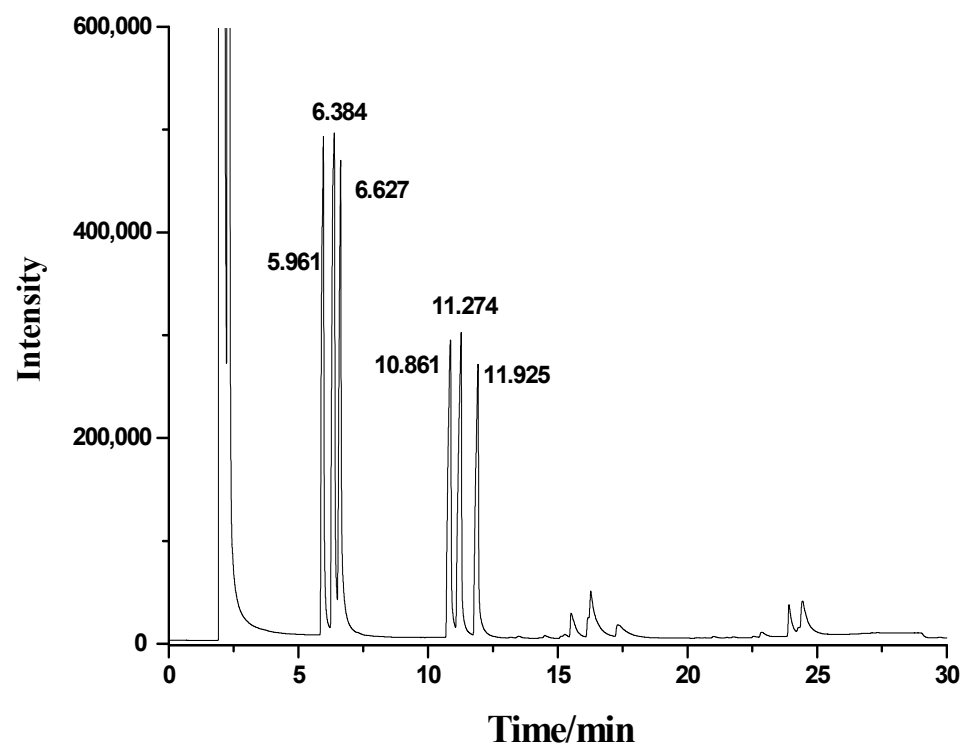

Figure 1. GC trace of standard monosaccharides.

The retention times of the monsaccharides were determined as $5.961 \mathrm{~min}$ for rhamnose, $6.384 \mathrm{~min}$ for arabinose, $6.627 \mathrm{~min}$ for xylose, $10.861 \mathrm{~min}$ for mannose, $11.274 \mathrm{~min}$ for glucose and $11.925 \mathrm{~min}$ for galactose (Figure 1). A standard curve of glucose was obtained from a linear regression of the content of glucose (C, mg) and absorbance value (A) (Equation (1)).

$$
\mathrm{A}=5.8137 \mathrm{C}-0.00473\left(\mathrm{R}^{2}=0.9987\right)
$$


The regression was tested and showed a good linear relation in the content range of $0.0-96.0 \mu \mathrm{g} / \mathrm{mL}$ glucose. By comparison with the relative retention times of the six monosaccharide standards, the monosaccharide composition and their relative contents in 32 species of bamboo leaves were then determined by GC. The BLPS of samples No. 1-No. 32 is mainly composed of $42.6 \%-62.7 \%$ of xylose, $10.2 \%-24.6 \%$ of arabinose, $10.2 \%-21.2 \%$ of glucose, $7.7 \%-15.7 \%$ of galactose and very little rhamnose and mannose. Mannose was not detected in 11 samples: Nos. 3, 4, 7, 8, 10, 11, 13, 14, 18, 19, and No. 26, rhamnose and mannose both were not found in 10 samples: Nos. 15-17, 20-22, and 29-32, while other samples just had less than $6.7 \%$ of rhamnose and less than $2.2 \%$ of mannose. Another discovery was that samples No. 29-No. 32 of P. nigra (Lodd.) Munro (PN), P. vivax McClure (PV), Chimonobambusa quadrangularis (Fenzi) Makino (CQ), and P. bambussoides cv. Tanakae (PB) not only consisted of four kinds of monosaccharides (xylose, arabinose, glucose and galactose), but the content of galactose is also in a range of $21.5 \%-34.1 \%$, which is $2-3$ fold more than in samples No. 1-No. 28. Beside the chemical composition, a sulfuric acid-anthrone colorimetric assay showed the total polysaccharides content of the 32 samples was between $1.4 \%-5.4 \%$, and the total polysaccharides of PN, PV, CQ and PB ranged between $4.2 \%-5.4 \%$, meaning that among the 32 different species listed in Table 1 samples No. 29-No. 32 contained 2-3 fold more polysaccharides than No. 1-No. 28. Therefore, these four typical species were chosen to investigate the structural characterization of BLPS.

Table 1. The content of total polysaccharides and monosaccharides from 32 different varieties of bamboo leaves.

\begin{tabular}{|c|c|c|c|c|c|c|c|c|}
\hline No. & Varieties of Bamboo Leaves & $\begin{array}{c}\text { Total } \\
\text { Polysaccharides } \\
(\%) \\
\end{array}$ & $\begin{array}{c}\text { Rhamnose } \\
(\%)\end{array}$ & $\begin{array}{c}\text { Arabinose } \\
\text { (\%) }\end{array}$ & $\begin{array}{c}\text { Xylose } \\
(\%)\end{array}$ & $\begin{array}{c}\text { Mannose } \\
(\%)\end{array}$ & $\begin{array}{c}\text { Glucose } \\
\text { (\%) }\end{array}$ & $\begin{array}{c}\text { Galactose } \\
(\%)\end{array}$ \\
\hline 1 & $\begin{array}{l}\text { P. praecox C.D. } \\
\text { Chu et C.S. Chao }\end{array}$ & 1.4 & 3.2 & 14.0 & 48.8 & 4.7 & 15.9 & 13.1 \\
\hline 2 & CV. Ventricousinternode & 1.5 & 4.6 & 16.3 & 50.3 & 1.4 & 17.2 & 10.1 \\
\hline 3 & $\begin{array}{c}\text { Bambusa multiplex cv. } \\
\text { Alphonse-Karr }\end{array}$ & 1.5 & 2.7 & 16.4 & 44.2 & - & 20.7 & 15.7 \\
\hline 4 & P. elegans McClure & 1.6 & 1.1 & 15.9 & 56.1 & - & 15.3 & 11.3 \\
\hline 5 & $\begin{array}{l}\text { Sasa pygmaea (Miq.) } \\
\text { E. G. Camus }\end{array}$ & 1.6 & 2.5 & 17.4 & 55.5 & 0.9 & 13.6 & 9.7 \\
\hline 6 & $\begin{array}{c}\text { Pseudosasa viridula S. L. } \\
\text { Chen et G. Y. Sheng }\end{array}$ & 1.9 & 6.7 & 13.8 & 50.2 & 1.6 & 18.4 & 10.6 \\
\hline 7 & $\begin{array}{l}\text { P. heterocycla (Carr.) Mitford } \\
\text { cv. Pubescens }\end{array}$ & 1.9 & 2.6 & 14.2 & 58.5 & - & 16.1 & 8.3 \\
\hline 8 & P. vivax McClure Aureocaulis & 1.9 & 1.2 & 14.5 & 59.2 & - & 14.7 & 10.2 \\
\hline 9 & P. viridis & 2.0 & 2.1 & 15.2 & 62.7 & 0.8 & 10.2 & 8.6 \\
\hline 10 & $\begin{array}{c}\text { Bambusa albo-lineata } \\
\text { (McClure) Chia }\end{array}$ & 2.2 & 1.8 & 20.5 & 56.0 & - & 12.3 & 9.1 \\
\hline 11 & P. propinqua McClure & 2.2 & 1.1 & 17.0 & 56.2 & - & 15.1 & 10.2 \\
\hline 12 & P. glauca McClure & 2.2 & 1.4 & 14.5 & 57.5 & 1.3 & 16.0 & 8.9 \\
\hline 13 & Phyllostachys & 2.2 & 2.2 & 18.0 & 54.6 & - & 16.8 & 7.7 \\
\hline
\end{tabular}


Table 1. Cont.

\begin{tabular}{|c|c|c|c|c|c|c|c|c|}
\hline No. & Varieties of Bamboo Leaves & $\begin{array}{c}\text { Total } \\
\text { Polysaccharides } \\
\text { (\%) } \\
\end{array}$ & $\begin{array}{c}\text { Rhamnose } \\
(\%)\end{array}$ & $\begin{array}{c}\text { Arabinose } \\
\text { (\%) }\end{array}$ & $\begin{array}{c}\text { Xylose } \\
(\%)\end{array}$ & $\begin{array}{c}\text { Mannose } \\
\text { (\%) }\end{array}$ & $\begin{array}{c}\text { Glucose } \\
(\%)\end{array}$ & $\begin{array}{c}\text { Galactose } \\
(\%)\end{array}$ \\
\hline 14 & P. heterocycla cv. Huamozhu & 2.3 & 0.6 & 14.2 & 56.4 & - & 19.9 & 8.5 \\
\hline 15 & P. propinqua McClure & 2.5 & - & 14.7 & 56.7 & - & 17.6 & 10.8 \\
\hline 16 & Bambusa ventricosa McClure & 2.7 & - & 19.6 & 52.8 & - & 16.2 & 11.4 \\
\hline 17 & $\begin{array}{c}\text { Bambusa multiplex (Lour.) } \\
\text { Raeusch. ex Schult. }\end{array}$ & 2.8 & - & 17.6 & 48.9 & - & 20.6 & 12.9 \\
\hline 18 & $\begin{array}{l}\text { Sinobambusa } \\
\text { tootsik(sieb.) Makino }\end{array}$ & 2.8 & 2.3 & 15.9 & 47.6 & 1.6 & 20.0 & 12.4 \\
\hline 19 & P. heterocycla (Carr.) Mit Ford & 2.8 & 1.3 & 13.6 & 58.0 & - & 16.4 & 10.4 \\
\hline 20 & Pseudosasa amabilis (McClure) & 2.9 & - & 18.6 & 60.2 & - & 11.7 & 9.5 \\
\hline 21 & $\begin{array}{c}\text { P. aureosuleata } \\
\text { McClure cv. Pekinensis }\end{array}$ & 2.9 & - & 14.5 & 57.5 & - & 19.0 & 8.9 \\
\hline 22 & $\begin{array}{c}\text { P. iridescins C.Y.Yao et } \\
\text { S.Y.Chen }\end{array}$ & 2.9 & - & 17.2 & 57.2 & - & 16.8 & 8.5 \\
\hline 23 & P. aureosulcata f. spectabilis & 3.1 & 6.7 & 10.2 & 48.9 & 1.2 & 21.2 & 11.5 \\
\hline 24 & P. gramineus (Bean) Nakai & 3.2 & 1.8 & 15.7 & 53.7 & 0.6 & 19.6 & 8.2 \\
\hline 25 & Bambusa rutila McClure & 3.3 & 3.7 & 11.3 & 55.9 & 0.4 & 18.1 & 10.5 \\
\hline 26 & $\begin{array}{c}\text { Pleioblastus } \\
\text { amarus (Keng) keng }\end{array}$ & 3.7 & 0.8 & 21.2 & 52.4 & - & 14.2 & 11.4 \\
\hline 27 & $\begin{array}{c}\text { Pleioblastus kongosanensis f. } \\
\text { aureostriaus }\end{array}$ & 3.9 & 4.7 & 17.6 & 47.9 & 0.5 & 16.2 & 12.9 \\
\hline 28 & Cyperus alternifolius & 3.9 & 5.3 & 15.7 & 53.7 & 2.2 & 12.3 & 10.8 \\
\hline 29 & P. nigra (Lodd.) Munro & 5.4 & - & 15.4 & 30.2 & - & 20.1 & 34.1 \\
\hline 30 & P. vivax McClure & 4.7 & - & 21.3 & 33.2 & - & 17.4 & 27.8 \\
\hline 31 & $\begin{array}{c}\text { Chimonobambusa } \\
\text { quadrangularis (Fenzi) Makino }\end{array}$ & 4.6 & - & 21.6 & 29.8 & - & 16.8 & 31.4 \\
\hline 32 & P. bambussoides cv.Tanakae & 4.2 & - & 24.6 & 32.6 & - & 20.8 & 21.5 \\
\hline
\end{tabular}

\subsection{Purification of BLPS by Sevag and Ion Exchange Resin}

The pulverized samples of the four varieties of bamboo leaves were extracted in hot water with the aid of ultrasound. The yield of polysaccharide extract was over 98\%. Decolorized polysaccharides were prepared from the precipitate fraction (DPS-1) and the clear filtrate (DPS-2) by ethanol precipitation, centrifugation and resin decolorization. The Sevag method (chloroform- $n$-butanol $=4: 1$, $\mathrm{v} / \mathrm{v}$ ) could remove over $95 \%$ of the free bamboo protein in $80 \%$ ethanol. In general, the decolorization of plant polysaccharides is very difficult to accomplish due to the presence of mixed deep colored plant polyphenols. The typical decolorization methods used are ion exchange, oxidation, metal complexes, and adsorption (cellulose, diatomaceous earth, activated carbon, etc.).

Ion exchange resins are the most commonly used decolorizing agents, and can adsorb yellow pigments like flavonoids, carotenoids, cyanidins etc. and plant polyphenols. Compared with the weakly polar macroporous resin D860021 and non-polar macroporous resin DM-2, the macroporous anion 
exchange resin D941 has the best decolorization effect on crude polysaccharide extracts and gave the highest decolorization rate of $70.30 \%$. The retention rate of polysaccharides approached $86.37 \%$, while the decolorization rates achieved with D860021 and DM-2 were just 42.85\% and $19.93 \%$, respectively. The key reason was that the colored impurities are mostly positively changed polyphenol molecules, which are very easily absorbed and exchanged to form ionic bonds with the weakly basic anionic resin. Therefore, the yields of DPS- 1 and DPS-2 were with on average 3.2\%-3.8\%. The dynamic adsorption curve of D941 is shown in Figure 2. When a crude polysaccharide solution of $25 \mathrm{mg} / \mathrm{mL}$ was passed through the D941 column at a speed of 3-5 $\mathrm{mL} / \mathrm{min}$, and the effluent volume of the sample approached 2.55 times the column volume, the resin reached saturation, this was the point was where the D941 column absorbed the polysaccharides.

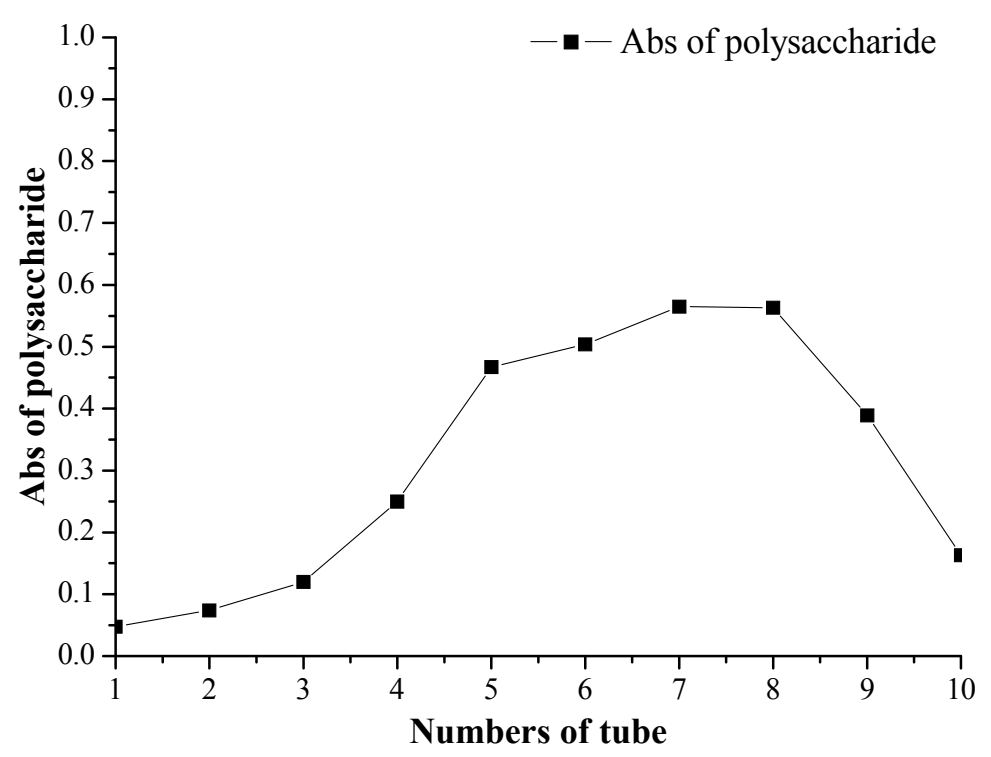

Figure 2. The dynamic adsorption of polysaccharide solution of Phyllostachys nigra (PN) on D941.

\subsection{Seperation of DPS by DEAE-52 Cellulose and Sephadex Gel Chromatography}

A DEAE-52 cellulose column was adopted to separate DPS from the four varieties PN, PV, CQ and PB. The DEAE-52 column was eluted with a gradient of aqueous $\mathrm{NaCl}$ solution $(0.1,0.3$ and $0.5 \mathrm{mg} / \mathrm{mL}$ ) at a flow rate of $1 \mathrm{~mL} / \mathrm{min}$. Due to the low yields and deep color of the $\mathrm{NaCl}$ eluate, the emphasis was to investigate the water eluate, and the largest peak was collected from tubes No. 1-No. 14 to separate the highest concentration of polysaccharides (Figure 3). The total polysaccharides of BLPS- 1 and BLPS-2 ranged from $65.55 \%-72.83 \%$ and $70.23 \%-78.77 \%$ by DEAE-52 cellulose separation of DPS-1 and DPS-2, respectively. 

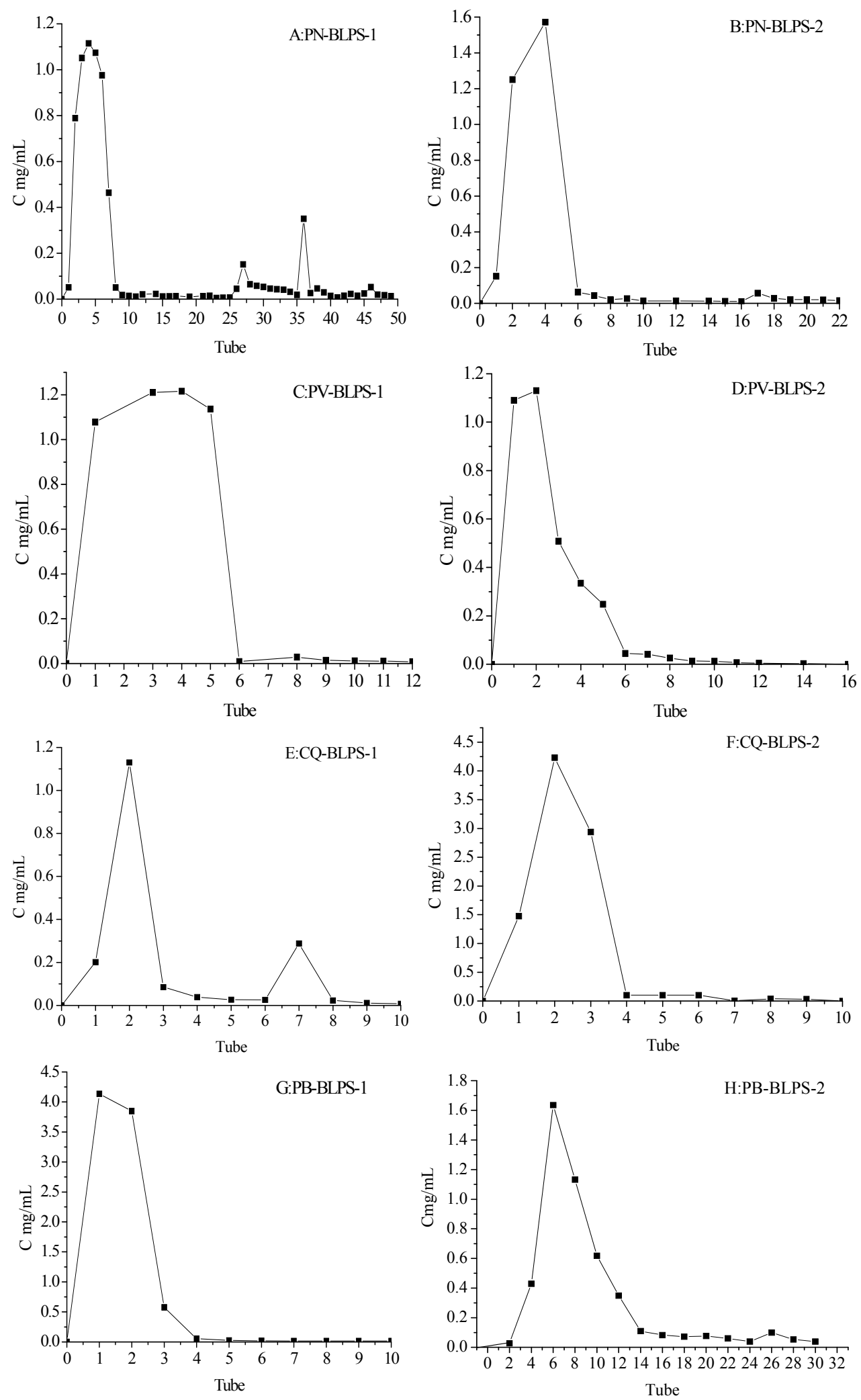

Figure 3. Separation of DPS from four varieties of bamboo leaves. (A,B) from Phyllostachys nigra (PN); (C,D) from Phyllostachys vivax (PV); (E,F) from Chimonobambusa quadrangularis (Fenzi) Makino (CQ), (G,H) from Phyllostachys bambusoides (PB) by a DEAE-52 cellulose column. 
In order to obtain high purity polysaccharide, the water-eluted polysaccharide fractions of the DEAE-52 cellulose column were further separated by Sephadex G-100 washed with $\mathrm{H}_{2} \mathrm{O}$ and $\mathrm{NaCl}$ solution. Most of the BLPS was concentrated in the water eluate, and only a small amount of polysaccharide was distributed in the $\mathrm{NaCl}$ elute (PV and $\mathrm{PB}$ ), so the largest peak was collected from tubes No. 1-No. 10 to obtain $90.36 \%-91.28 \%$ of polysaccharides from PN, tubes No. $1-$ No. 6 to obtain $94.51 \%-95.33 \%$ of polysaccharides from PV, tubes No. 4-No. 18 to obtain $92.77 \%-93.91 \%$ of polysaccharides from CQ and tubes No. $1-$ No. 6 to obtain $96.20 \%-96.87 \%$ of polysaccharides for PB in Figure 4. Then the high purity PBLPS-1 and PBLPS-2 separated by Sephadex G-100 was used for the identification of their chemical structure by gel chromatography, Fourier transform infra-red spectroscopy (FTIR) and $\mathrm{NaIO}_{4}-\mathrm{HIO}_{4}$ oxidation reactions.
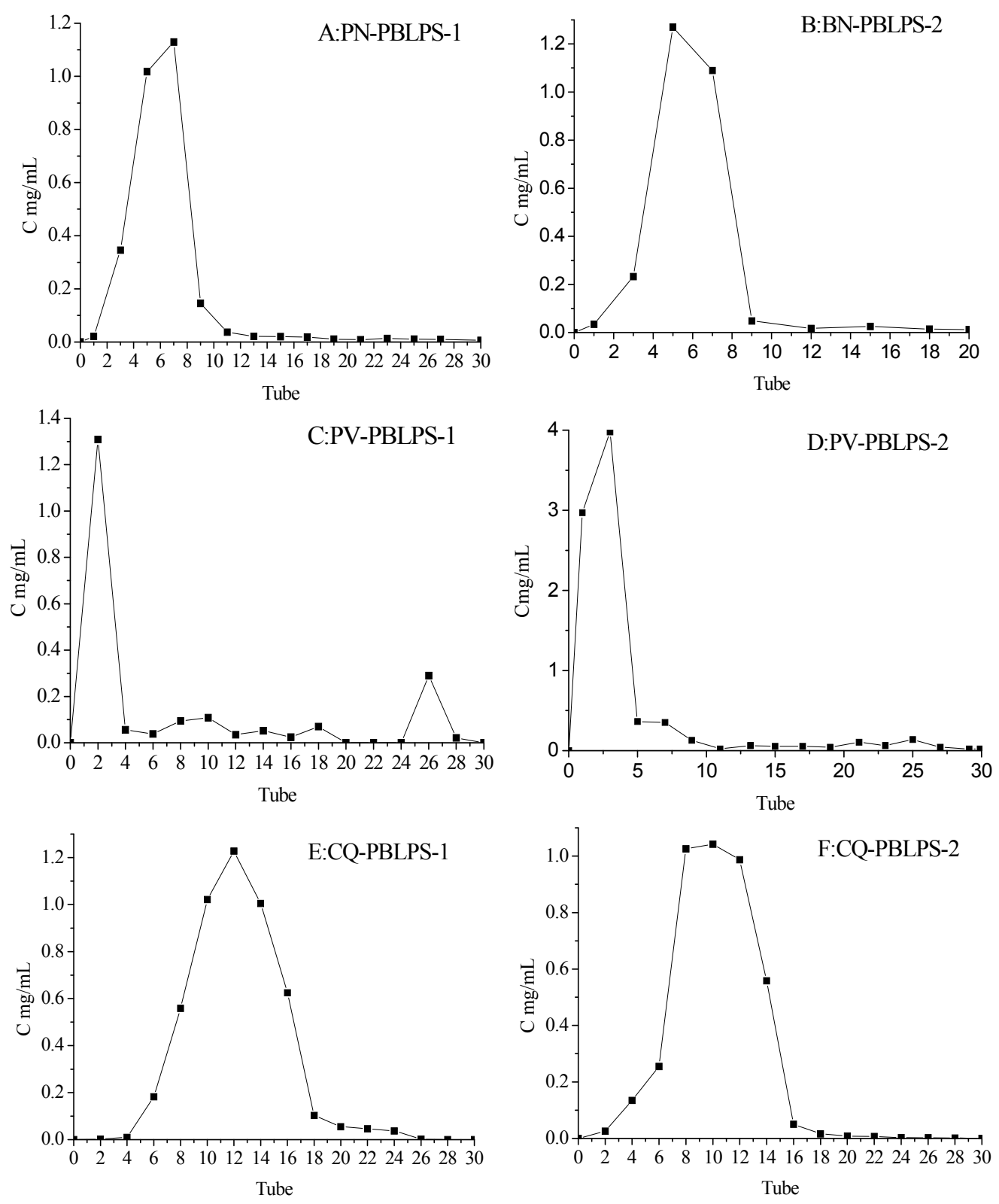

Figure 4. Cont. 

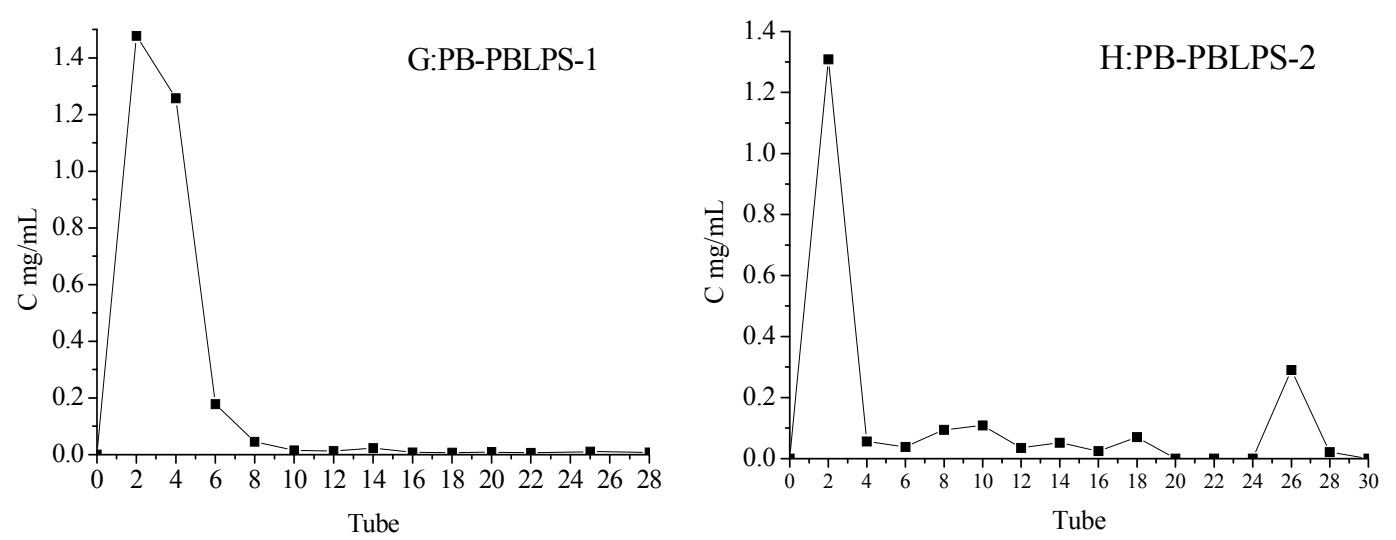

Figure 4. Enrichment and separation of BLPS by Sephadex G-100 from the four kind viarieties of bamboo leave: PBLPS: Purified BLPS. (A,B) from Phyllostachys nigra (PN); (C,D) from Phyllostachys vivax (PV); (E,F) from Chimonobambusa quadrangularis (Fenzi) Makino (CQ); (G,H) from Phyllostachys bambusoides (PB).

\subsection{Molecular Weight of PBLPS}

Glucose dextran-T standards show a very good linear relationship between the logarithm of the standard molecular weight in a range of 180-160 $\times 10^{4}$ and retention time. The standard calibration curve for the series of dextran-T compounds gave a regression coefficient, $R^{2}=0.9990$ (Equation (2)):

$$
\mathrm{y}=-0.4644 \mathrm{x}+9.6391\left(R^{2}=0.9990\right)
$$

The molecular weight of PBLPS-1 and PBLPS-2 from the four varieties of bamboo leaves was determined by using GPC HPLC (Figure 5). This showed that PN-PBLPS-1, PN-PBLPS-2, PV-PBLPS-1, CQ-PBLPS-1 and PB-PBLPS-1 were homogeneous polysaccharides with molecular weights of $2.04 \times 10^{4}, 3.51 \times 10^{3}, 1.15 \times 10^{4}, 8.75 \times 10^{4}$, and $1.48 \times 10^{4}$, respectively, while the others were heterogeneous polysaccharides. PV-PBSP-2 contained two kinds of polysaccharides with molecular weights of $1.89 \times 10^{4}$ and $2.06 \times 10^{3}$, CQ-PBSP-2 and PB-PBSP-2 consisted of three types of polysaccharide. CQ-PBSP-2 was a mixture of components with molecular weights of $2.72 \times 10^{4}$, $1.60 \times 10^{4}$ and $2.07 \times 10^{3}$. PB-PBSP-2 also had three compounds with molecular weights of $5.85 \times 10^{4}, 4.88 \times 10^{4}$ and $2.07 \times 10^{3}$. The results also showed that molecular weight of PBSP-1 obtained from the alcohol precipitation was higher than that of PBSP-2 from the alcohol filtrate. The key reason for this is the different separation methods used. High molecular weight PBSP-1 was a homogeneous polysaccharide, while small molecular weight PBSP-2 was a heterogeneous polysaccharide. Due to more complex constituents and structure of PBSP-2, further studies on the structure and bioactivity of PBSP-2 will be performed in the future. 

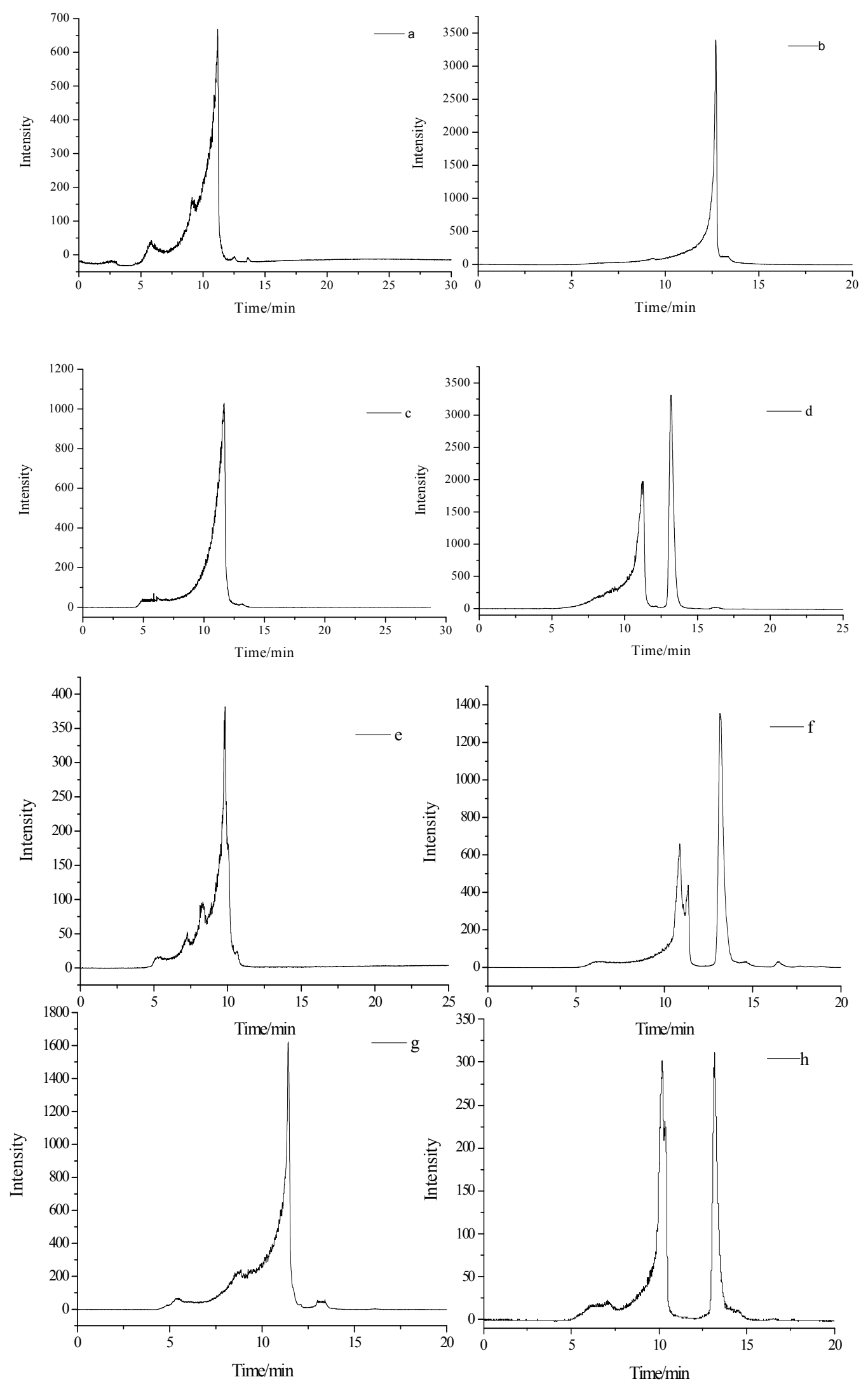

Figure 5. GP-HPLC of PBLPS from the four varieties of bamboo leave: PBLPS: Purified BLPS. (a,b) from Phyllostachys nigra (PN); (c,d) from Phyllostachys vivax (PV); (e,f) from Chimonobambusa quadrangularis (Fenzi) Makino (CQ); (g,h) from Phyllostachys bambusoides (PB). 


\subsection{Fourier Transform Infra-Red (FTIR) Spectroscopy of PBLPS}

As PBSP-1 was a homogeneous polysaccharide, it was further investigated to elucidate its structure elucidation. Figure 6 shows the FTIR spectra of PBLPS from the four kinds of bamboo leaves. It was found that the four kinds of PBSP-1 had similar IR absorption bands as follows $\left(\mathrm{cm}^{-1}\right)$ : 3375.37 , 1647.53, 1430.02, 1385.56, 1099.54 and 855.08 for PN-PBLPS-1; 3230.70, 1617.45, 1405.52, 1126.08, 1096.84 and 856.05 for PV-PBLPS-1; 3395.95, 2937.59, 1790.30, 1643.66, 1432.21, 1377.1, 1084.46 and 853.55 for CQ-PBLPS-1; 3387.91, 2932.82, 1795.70, 1614.00, 1419.18, 1115.99, 897.09 and 853.82 for PB-PBLPS-1. Broad peaks in the $3230.70-3395.95 \mathrm{~cm}^{-1}$ range are assigned to the hydroxyl stretching vibration. The absorption at $2937.59-2937.59 \mathrm{~cm}^{-1}$ is assigned to $\mathrm{C}-\mathrm{H}$ stretching vibration, the shoulder peak at $1790.30-1795.70 \mathrm{~cm}^{-1}$ is due to the $\mathrm{C}=\mathrm{O}$ stretching vibration in polysaccharide polymers, while the peak at $1614.00-1647.53 \mathrm{~cm}^{-1}$ is also a $\mathrm{C}=\mathrm{O}$ stretching vibration of a -CHO group, which is a characteristic absorption peak of uronic acid structures. The absorption of 1405.52-1432.21 $\mathrm{cm}^{-1}$ is the $\mathrm{C}-\mathrm{O}$ stretching vibration of a $-\mathrm{COOH}$ group, the peak at $1377.10-1385.56 \mathrm{~cm}^{-1}$ is the $\mathrm{C}-\mathrm{H}$ deformation vibration. Absorptions at $1115.99 \sim 1126.08 \mathrm{~cm}^{-1}$ correspond to the bending vibration of the $\mathrm{C}-\mathrm{OH}$ group and the peak at $1084.46-1099.54 \mathrm{~cm}^{-1}$ is the C-O-C stretching vibration, which are characteristic absorption peaks of pyranoside linkage structures $[17,18]$.

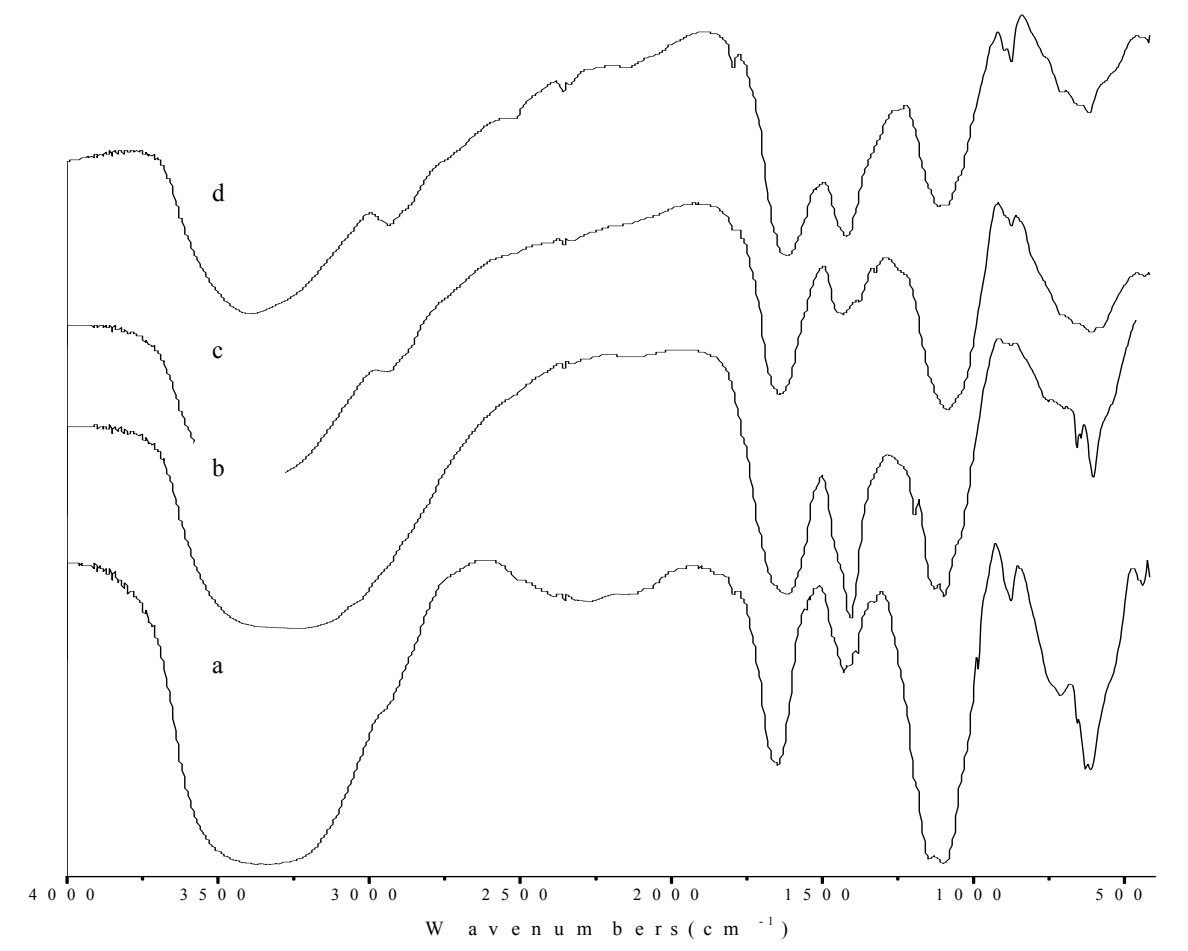

Figure 6. FTIR of PBLPS-1 from the four varieties of bamboo leave: (a) PBLPS-1 of Phyllostachys nigra (PN); (b) PBLPS-1 of Phyllostachys vivax (PV); (c) PBLPS-1 of Chimonobambusa quadrangularis (Fenzi) Makino (CQ); (d) PBLPS-1 of Phyllostachys bambusoides (PB). 
In carbohydrate analysis by IR, $\alpha$ and $\beta$ conformers can be clearly distinguished by the anomeric region-vibrational bands in the 950 to $750 \mathrm{~cm}^{-1}$ region, where $870-840 \mathrm{~cm}^{-1}$ corresponds to the $\alpha$ configuration, while the $\beta$ configuration lies around $890 \mathrm{~cm}^{-1}[19,20]$. In this study, the peak at $853.55-856.05 \mathrm{~cm}^{-1}$ is the $\mathrm{C}$-H bending vibration of $\alpha$-galactopyranose linkages in all PBLPS, while the $1.897 .09 \mathrm{~cm}^{-1}$ and $710.74 \mathrm{~cm}^{-1}$ absorption peaks are the $\mathrm{C}-\mathrm{H}$ deformation vibration and C-O-C stretching vibrations of $\beta$-D-galactopyranose linkages only present in PB-PBLPS-1, so apart from PB-PBLPS-1, which is a mixture of $\alpha$-galactopyranose and $\beta$-D-glucopyranose linkages, the others (PN-PBLPS-1, PV-PBLPS-1, CQ-PBLPS-1) just have $\alpha$-galactopyranose linkages. All PBLPS-1 are homogeneous polysaccharides with galactopyranose linkages. According to the molecular weight of PBLPS-1, the polymerization numbers of galactose units are 113, 64, 486, 82 for PN-PBLPS-1, PV-PBLPS-1, CQ-PBLPS-1, and PB-PBLPS-1, respectively.

\section{6. $\mathrm{NaIO}_{4}-\mathrm{HIO}_{4}$ Oxidation and Smith Degradation of PBLPS-1}

$\mathrm{NaIO}_{4}-\mathrm{HIO}_{4}$ oxidation was used to determine the glycosidic bond linkages and non-carbohydrate residues in polysaccharides by estimating the number of moles of periodate consumed and the amount of formate produced in the reaction. Periodate oxidation involves the simultaneous oxidation and cleavage of carbon to carbon bonds that have adjacent free hydroxyl groups in polysaccharides, the products of periodate oxidation include homologous aldehydes of the polysaccharide, formaldehyde or formate, The cleavage reaction of one molecule of carbon to carbon bonds consumes one molecule of periodate. The $\mathrm{NaIO}_{4}-\mathrm{HIO}_{4}$ standard curve showed a very good linear relationship between the standard concentration and UV absorbance at $223 \mathrm{~nm}$. The standard calibration curve for the consumption of $\mathrm{NaIO}_{4}$ gave a regression coefficient, $R^{2}=0.9992$ (Equation (3)):

$$
\mathrm{y}=0.0327 \mathrm{x}-0.0077\left(R^{2}=0.9992\right)
$$

The consumption of $\mathrm{IO}_{4}{ }^{-}$and production of HCOO for PBLPS-1 from the four kinds of bamboo leaves is shown in Figure 7. The amount of formic acid generated became almost stable 3 days later, and $\mathrm{IO}_{4}{ }^{-}$consumption was basically unchanged after 6 days. All PBLPS-1 were oxidized into formic acid. $\mathrm{IO}_{4}{ }^{-}$consumption was twice as great as the amount of formic acid, which indicated that all PBLPS-1 mainly contained $(1 \rightarrow 6)$ galactopyranose linkages. All PBLPS-1 were shown to be homogeneous polysaccharides with galactopyranose linkages and an average molecular weight $\left(\mathrm{M}_{\mathrm{r}}\right)$ range of $1.15 \times 10^{4}-8.75 \times 10^{4}$, while all PBLPS-2 were heterogeneous polysaccharides with a small $\mathrm{M}_{\mathrm{r}}$ range of $2.06 \times 10^{3}-5.85 \times 10^{4}$. 

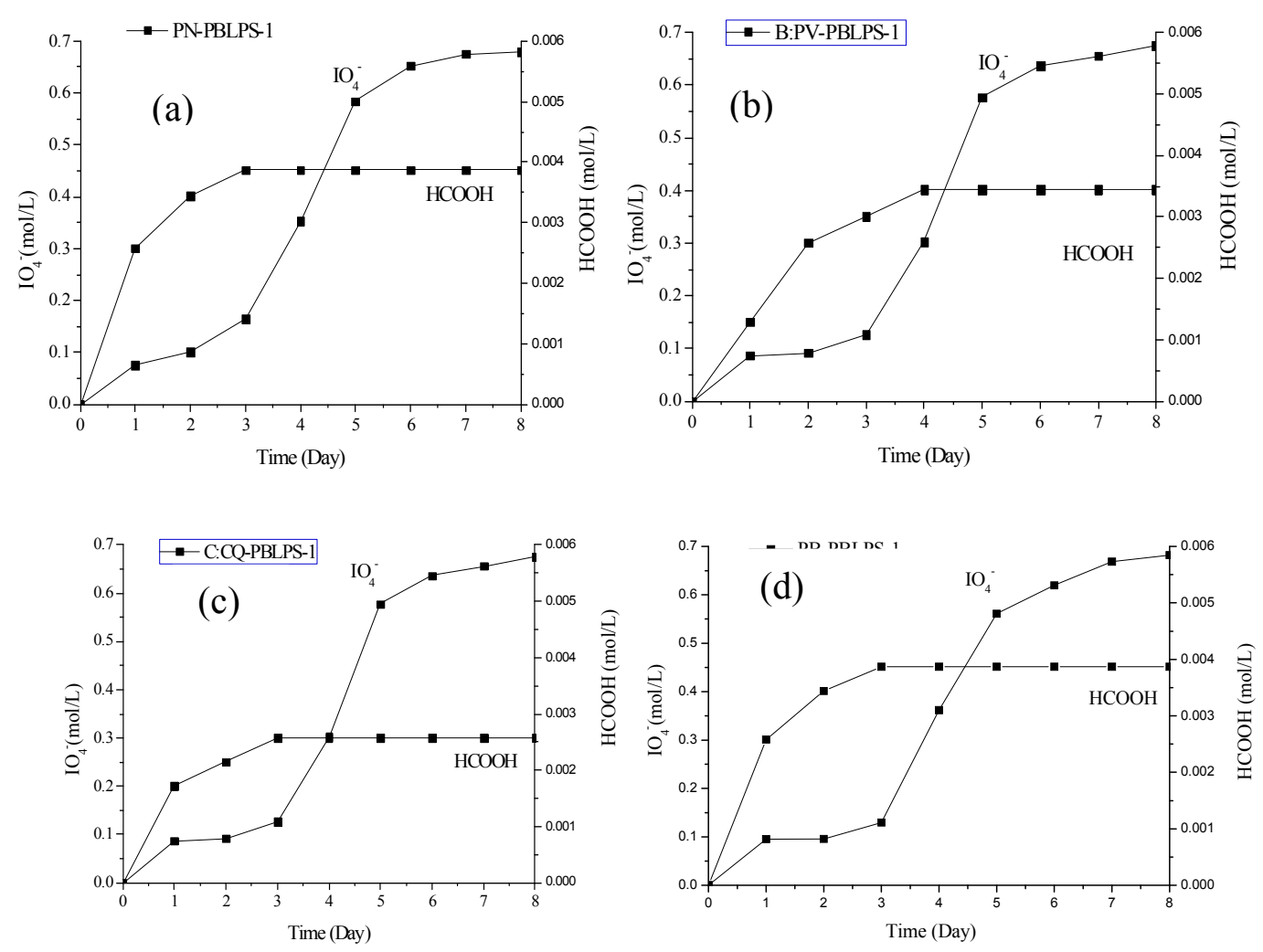

Figure 7. Consumption of $\mathrm{IO}_{4}^{-}$and production of HCOO for PBLPS-1 from the four varieties of bamboo leave: (a) PN-PBLPS-1 of Phyllostachys nigra (PN) (b) PV-PBLPS-1 of Phyllostachys vivax (PV) (c) CQ-PBLPS-1 of Chimonobambusa quadrangularis (Fenzi) Makino (CQ) (d) PB-PBLPS-1 of Phyllostachys bambusoides (PB).

\section{Experimental}

\subsection{Materials}

Thirty two samples of bamboo leaves were collected from Anji Country in Zhejiang province of Southern China in October, 2012. They were dried in an oven under circulated air at $50{ }^{\circ} \mathrm{C}$ for $24 \mathrm{~h}$ before use and crushed into powder of 60-80 mesh particle size.

\subsection{Experimental Apparatus and Chemicals}

Sulfuric acid-anthrone (anthrone $0.2 \mathrm{~g}$ and $80 \%$ sulfuric acid $100 \mathrm{~mL}$ ) was used to determine the content of polysaccharides in bamboo leaves using a 722 spectrophotometer (Shanghai Spectrum Instruments Co., Ltd, Shanghai, China). The composition and structure of BLPS were elucidated by GC using a Shimadzu (Shimadzu (China) Co., Ltd., Beijing, China) instrument. Fourier Transform Infra-Red (FTIR) and Gel HPLC were from Waters (Milford, MA, USA). The standard compounds of rhamnose, arabinose, xylose, mannose, galactose, glucose were purchased from Sigma Chemical Company (Beijing, China) and other chromatographic reagents were purchased from local chemical suppliers. 


\subsection{Experimental Methods}

\subsubsection{Colorimetric Analysis of BLPS}

Different samples of bamboo leaves $(2.0 \mathrm{~g})$ were weighed into a round bottom flask, and extracted with the aid of ultrasound at a solid-liquid ratio of $1: 10(\mathrm{~g} / \mathrm{mL})$, two times, $30 \mathrm{~min}$ at $80{ }^{\circ} \mathrm{C}$ each time. The extracting solution was mixed and condensed under vacuum, then diluted with distilled water to $25 \mathrm{~mL}$ in a volumetric flask, then $1.0 \mathrm{~mL}$ of the diluted solution was placed in a $10 \mathrm{~mL}$ tube with stopper. Then, the steps above were repeated. The polysaccharide content of bamboo leaves (BLPSC) were calculated using Equation (4). Anthrone $(0.2 \mathrm{~g}$ ) was diluted with $80 \%$ sulfuric acid to $100 \mathrm{~mL}$ and mixed, then a quantified amount of glucose was diluted to $0.12 \mathrm{mg} / \mathrm{mL}$ with distilled water. The standard solution of glucose was divided into portions of $0.0,0.1,0.2,0.3,0.4,0.6$ and $0.8 \mathrm{~mL}$ in $10 \mathrm{~mL}$ tubes with stopper, and then diluted in turn to $10 \mathrm{~mL}$ with deionized water. Then, $4 \mathrm{~mL}$ sulfuric acid-anthrone was measured out and added to each tube cooled with ice, reacted for about $10 \mathrm{~min}$ in boiling water, then cooled to ambient temperature. The absorbance value (A) was measured at $620 \mathrm{~nm}$ :

$$
\text { BLPSC }=\frac{C \times v}{w} \times 100 \%
$$

$\mathrm{C}$ : concentration of polysaccharides from the linear regression equation, $\mu \mathrm{g} / \mathrm{mL}$

$\mathrm{V}$ : volume of polysaccharide, $\mathrm{mL}$

w: sample weight of bamboo leaves, $g$

\subsubsection{Gas Chromatography}

The samples were hydrolyzed with $1.5 \% \mathrm{H}_{2} \mathrm{SO}_{4}$ solution, and derivatized by acetylation according to [9]. A GC system (Shimadzu (China) Co., Ltd.) instrument) was used to analyze the monosaccharide composition of the bamboo sample polysaccharides using a HP-5 capillary column $(30 \mathrm{~m} \times 0.32 \mathrm{~mm} \times 0.25 \mu \mathrm{m})$ at $250{ }^{\circ} \mathrm{C}$ of oven temperature and $300{ }^{\circ} \mathrm{C}$ of detector temperature with FID detector and $1 \mathrm{~mL} / \mathrm{min}$ of carrier gas. Temperature programming: $180{ }^{\circ} \mathrm{C} \rightarrow 2{ }^{\circ} \mathrm{C} / \mathrm{min} \rightarrow 220{ }^{\circ} \mathrm{C}$ $(1 \mathrm{~min}) \rightarrow 5^{\circ} \mathrm{C} / \mathrm{min} \rightarrow 250^{\circ} \mathrm{C}(2 \mathrm{~min})$.

\subsubsection{Extraction and Purification of BLPS}

Pulverized samples (200 g) of the four varieties of bamboo leaves: Phyllostachys nigra (PN), Phyllostachys vivax (PV), Chimonobambusa quandrangularis (Fenzi) Makino (CQ) and Phyllostachys bambusoides (PB), were extracted with the help of ultrasoound wave with water at a solid-liquid ratio of 1:10 (g/mL), two times, $30 \mathrm{~min}$ at $80{ }^{\circ} \mathrm{C}$ each time. The extracting solutions were mixed and concentrated under vacuum. $80 \%$ ethanol was added to the concentrated solution with continuous stirring, and the precipitated fractions were centrifuged to produce the crude polysaccharides extract, then the crude extract was washed with hydrochloric acid to remove proteins, and decolorized with D941 resin and lyophilized, to give the extract of decolorized polysaccharides (DPS-1) according to [11]. The same purification method was used to get the clear filtrate from $80 \%$ ethanol precipitated crude polysaccharide. The clear filtrate was condensed, then $80 \%$ ethanol was added to precipitate the 
polysaccharides of the concentrate and centrifuged again. The extract of decolorized polysaccharides (DPS-2) was also prepared from the clear $80 \%$ ethanol filtrate.

\subsubsection{Ion-Exchange and Sephadex Gel Chromatography of DPS}

DPS-1 and DPS-2 from the four kinds of bamboo leaves, respectively, were dissolved in deionized water with a polysaccharide concentration of $15 \mathrm{mg} / \mathrm{mL}$, the solution was loaded onto the treated DEAE-52 cellulose column $(3.8 \mathrm{~cm}$ i.d. $\times 120 \mathrm{~cm}$, Pharmacia, Shanghai, China) equilibrated with deionized water. Then the DEAE-52 column was eluted with a gradient of aqueous $\mathrm{NaCl}$ solution $(0.1$, 0.3 , and $0.5 \mathrm{mg} / \mathrm{mL}$ ) at a flow of $1 \mathrm{~mL} / \mathrm{min}$. Eluted fractions were collected in $20 \mathrm{~mL}$ tubes and the polysaccharide content was monitored by the anthrone-sulfuric acid method.

The polysaccharide fractions eluted from the DEAE-52 cellulose were lyophilized, then dissolved in deionized water with a polysaccharide concentration of $5 \mathrm{mg} / \mathrm{mL}$, and the solution was loaded onto a treated Sephadex G-100 coumn $\left(2.2 \mathrm{~cm}\right.$ i.d. $\times 80 \mathrm{~cm}$, Pharmacia), then washed with $\mathrm{H}_{2} \mathrm{O}$ at a flow rate of $0.33 \mathrm{~mL} / \mathrm{min}$. The same method was used to analyze the polysaccharide content of the eluted fractions collected in $20 \mathrm{~mL}$ tubes. The purified polysaccharide fractions (PBLPS) were concentrated and lyophilized, then PBLPS-1 and PBLPS-2 were prepared for the identification of their chemical structure by gel chromatography, Fourier transform infra-red spectroscopy (FTIR) and oxidation with $\mathrm{NaIO}_{4}-\mathrm{HIO}_{4}[20]$.

\subsubsection{Determination of Relative Molecular Weight of PBLPS}

Every sample of PBLPS-1 and PBLPS-2 $(3.0 \mathrm{mg})$ was dissolved in of distilled water $(2.0 \mathrm{~mL})$ at $80{ }^{\circ} \mathrm{C}$ by the aid of ultrasound for $5 \mathrm{~min}$, then filtered through a $0.45 \mu \mathrm{m}$ membrane. The molecular weight of PBLPS-1 and PBLPS-2 was determined using gel permeation HPLC equipment (Agilent 1200) equipped with a detector of ELSD 3300/2000 and a TSK-gel G5000 column $(7.8 \mathrm{~mm} \times 30 \mathrm{~cm}$, Tosoh (Shanghai)Co. Ltd., Shanghai, China). Standard T-series dextrans with molecular weights of 10, $40,70,150,220,300,380 \mathrm{kDa}$ were used at $1 \%(\mathrm{w} / \mathrm{v})$ concentration. The standard solution of the T-series and glucose $(10 \mu \mathrm{L})$ were passed through the column using isocratic mode at a flow rate of $0.8 \mathrm{~mL} / \mathrm{min}$ with deionized water as a mobile phase at a column temperature of $30^{\circ} \mathrm{C}$, the elution times were plotted against the logarithm of their respective molecular weights.

\subsubsection{Fourier Transform Infra-Red Spectroscopy (FTIR) of PBLPS}

PBLPS-1 was directly measured by FTIR spectroscopy in a range of 4000 to $400 \mathrm{~cm}^{-1}$ using $\mathrm{KBr}$ disks containing 1\% finely ground samples on a Nicolet 550 FT-IR spectrometer (Thermo Nicolet, Waltham, MA, USA). FTIR is used to investigate the vibrations of molecules and polar bonds between the different atoms, types of monosaccharide, glycosidic bonds and functional groups [20].

\subsection{7. $\mathrm{NaIO}_{4}-\mathrm{HIO}_{4}$ Oxidation and Smith Reduction of PBLPS}

Standard solutions of $0.15 \mathrm{~mol} / \mathrm{L}$ sodium periodate and sodium iodide $(50 \mathrm{~mL})$ were prepared. Sodium periodate solution and sodium iodide solution were mixed in proportions of 5:0, 4:1, 3:2, 2:3, $1: 4$, and $0: 5(\mathrm{v} / \mathrm{v})$, respectively, and a sample of the mixture $(0.4 \mathrm{~mL})$ was placed in a $100 \mathrm{~mL}$ volumetric 
flask, deionized water added to dilute the solution to the mark, then the standard curve of sodium periodate and sodium iodide solution was produced by the UV absorbance value measured at $223 \mathrm{~nm}$.

PBLPS sample (30 mg) was placed in $250 \mathrm{~mL}$ brown flask, and $0.015 \mathrm{~mol} / \mathrm{L}$ solution of sodium periodate $(60 \mathrm{~mL})$ was added into the flask with shaking to dissolve the sample, then placed in the dark at $4{ }^{\circ} \mathrm{C}$ with intermittent oscillation. Aliquots $(0.2 \mathrm{~mL})$ of reaction solution were placed in a $50 \mathrm{~mL}$ volumetric flask at predetermined time intervals for UV analysis, and the rest was used for Smith hydrolysis. The amount of formic acid generated in the reaction was determined by titrating $5.0 \mathrm{~mL}$ of the reaction solution with $0.0086 \mathrm{~mol} / \mathrm{L}$ sodium hydroxide, adding 2 drops of ethylene glycol, phenolphthalein as indicator for $30 \mathrm{~min}$. According to the method [21], the products of periodate oxidation was dialyzed for $48 \mathrm{~h}$, and concentrated under reduced pressure below $40{ }^{\circ} \mathrm{C}$ to about $10 \mathrm{~mL}$ of total volume, $1 \mathrm{~mol} / \mathrm{L} \mathrm{H}_{2} \mathrm{SO}_{4}$ was added $(2 \mathrm{~mL})$ and completely hydrolyzed at $100{ }^{\circ} \mathrm{C}$ for $8 \mathrm{~h}$. The hydrolysate was neutralized with $\mathrm{BaCO}_{3}$, then filtered. The filtrate was concentrated and determined by $\mathrm{GC}$ analysis after acetylation.

\section{Conclusions}

The total polysaccharides of 32 samples of bamboo leaves was between $1.4 \%$ and $5.4 \%$, while BLPSC of PN, PV, CQ and PB was 4.2\%-5.4\%, which was about 2-3 fold more than in samples No. 1-No. 28 of the different species. Particularly the content of galactose for the four typical bamboo leaves was in a range of $21.5 \%-34.1 \%$, which is also definetly 2-3 fold more than in No. 1-No. 28. Based on the results of sugars analysis, molecular weight determination, FTIR spectra, $\mathrm{NaIO}_{4}-\mathrm{HIO}_{4}$ oxidation and Smith degradation as well as the existing literature concerining the structural properties of bamboo polysaccharides, all PBLPS-1 are homogeneous polysaccharides with molecular weights of $10^{4}-10^{5} \mathrm{Da}$, while PBSP-2 are heterogeneous polysaccharides with two or three kinds of polysaccharides. PB-PBLPS- 1 is a mixture of $\alpha$-galactopyranose linkages and $\beta$-D-glucopyranose linkages with $\alpha-(1 \rightarrow 6)$ or $\beta-(1 \rightarrow 6)$ glycosidic bonds, while PN-PBLPS-1, PV-PBLPS-1, and CQ-PBLPS-1 are just $\alpha$-galactopyranose linkages of $\alpha$ - $(1 \rightarrow 6)$ glycosidic bonds.

In general, hemicelluoses or polysaccharides from bamboo wood or bamboo shoot consist of D-xylose, L-arabinose, D-galactose, D-mannose, D-glucuronic acid, 4- $O$-methyl-D-glucuronic acid, D-galacturonic acid and lesser amounts of L-rhamnose, L-fucose, and various $O$-methylated neutral sugars, which contain a backbone of D-xylopyranosyl residues, linked together by $\beta$ - $(1 \rightarrow 4)$-glycosidic bonds. These hemicellucosic polysaccharides have an average $\mathrm{Mr}$ range of over $10^{5} \mathrm{Da}$ and very weak physiological activity. However, the polysaccharides of bamboo leaves (BLPS) is a kind of bioactive heteropolysaccharide with relative medium molecular mass of less than $10^{4} \mathrm{Da}$. BLPS had been proved to have good antitumor physiological activity and has been used widely as edible and medicinal materials as well as cosmetic additives. This study found high content and bioactive polysaccharides in the four varieties P. nigra (Lodd.) Munro (PN), P. vivax McClure (PV), Chimonobambusa quadrangularis (Fenzi) Makino (CQ), and P. bambussoides cv. tanakae (PB). These bioactive polysaccharides are mainly composed of xylose, galactose, and glucose, furthermore, the structural characterization of mono-sugar link styles were preliminary elucidated as glucopyranose linkages with glycosidic bonds, therefore, this work will provide a basis to research the fine structure and biological activity of polysaccharides from these four typical kinds of bamboo leaves. 


\section{Acknowledgments}

The authors are thankful to the financial support of this work by international cooperation programme No. 2014DFR31300 and 0S2012GR0138.

\section{Author Contributions}

C.-Z.W. designed the study and performed the experimental work and data analyses. H.-Y.Z., W.-J.L. and J.-Z.Y. performed the experiments. H.-Y.Z. supervised the experimental work. All authors read and approved the final manuscript.

\section{Conflicts of Interest}

The authors declare no conflict of interest.

\section{References}

1. Aspinall, G.O.; Mahomed, R.S. The constitution of a wheat-straw xylan. J. Chem. Soc. 1954, 76, 1731-1734.

2. Sun, X.F.; Sun, R.C.; Fowler, P.; Baird, M.S. Extraction and characterization of original lignin and hemicelluloses from wheat straw. Agric. Food Chem. 2005, 53, 860-870.

3. Tatsuya, H.; Ayumi, T.; Akiko, H.; Fumihide, T.; Tomihisa, O. Antioxidant C-glycosyl flavones from the leaves of Sasa kurilensis varigantean. Phytochemistry 2008, 69, 1419-1424.

4. Yusuke, E.; Tadashi, I. Hemicelucosic polysaccharides from bamboo shoot cell-walls. Phytochemistry 1998, 49, 1675-1682.

5. Xue, Y.Q.; Yuan, K.; Zhu, M.X. GC-MS analysis of chemical constituents of the essential oil from Phyllostachys pubescens. Chin. J. Pharm. Anal. 2009, 29, 954-960.

6. Wang, H.B.; Yao, H.; Bao, G.H.; Zhang, H.P.; Qin, G.W. Flavone glucosides with immunomodulatory activity from the leaves of Pleioblastus amarus. Phytochemistry 2004, 65, 969-974.

7. Zhang, Y.; Jiao, J.J.; Liu, C.M.; Wu, X.Q.; Zhang, Y. Isolation and purification of four flavone $\mathrm{C}$-glycosides from antioxidant of bamboo leaves by macroporous resin column chromatography and preparative high-performance liquid chromatography. Food Chem. 2008, 107, 1326-1336.

8. Lu, B.Y.; Wu, X.Q.; Tie, X.W.; Zhang, Y.; Zhang, Y. Toxicology and safety of antioxidant of bamboo leaves. Part 1, Acute and subchronic toxicity studies on antioxidant of bamboo leaves. Food Chem. Toxicol. 2005, 43, 783-792.

9. Tang, L.L.; Ding, X.L. Study on extraction isolation and biological activity of bamboo-leaves polysaccharide. Food Res. Dev. 2000, 21, 8-10.

10. Cao, H.Q.; Yue, Y.D.; Peng, Z.H. Evaluation of extracts from bamboo for biological activity against CULEX PIPIENS PALLENS. Entomol. Sin. 2004, 11, 267-273.

11. Ikm, I.; Krylova, R.G.; Usvo, A.I. Preliminary investigation of the water-soluble polysaccharides from the leaves of the bamboo sasamorpha chiisanensis. Chem. Nat. Compd. 1987, 23, 33-36.

12. Kato, Y.; Shiozawa, R.; Takeda, S.; Ito, S.; Matsuda, K. Structural investigation of a $\beta$-D-glucan and a xyloglucan from bamboo—shoot cell—walls. Carbohydr. Res. 1982, 109, 233-248. 
13. Suzuki, S.; Saito, T.; Uchiyama, M.; Okiya, S. Isolation of hemicelluloses from Yakushima bamboo and their growth inhibitory activities against S180 tumor. Chem. Pharm. Bull. (Tokyo) 1968, 16, 2032-2039.

14. Ye, J.Z.; Chen, W.Y.; Wang, C.Z. Screening of Polysaccharide and study on their analysis forhigh quality bamboo leaves. Mod. Chem. Ind. 2008, 10, 268-270.

15. Feng, Y.C.; Wang, C.Z.; Chen, W.Y. Sutdy on Chemical Characteristics and Content of Polvsaccharides from Bamboo Leaves of Different Species. Chem. Ind. For. Prod. 2009, 29, $81-85$.

16. Lu, Z.; Xie, B. Analysis of the active components in bamboo leaves and the anti-microbial effect of their Extracts. J. Cent. South For. Univ. 2004, 24, 70-73.

17. Xu, X.; Chen, P.; Wang, Y. Chain conformation and rheological behavior ofan extracellular heteropolysaccharide Erwinia gum in aqueous solution. Carbohydr. Res. 2009, 344, 113-119.

18. Singthong, J.; Ningsanond, S.; Cui, S.W. Extraction and physicochemical characterization of polysaccharide gum from Yanang leaves. Food Chem. 2009, 114, 391-395.

19. Kacurakova, M.; Wilson, R.H. Developments in mid-infrared FTIR spectroscopy of selected carbohydrated. Carbohydr. Polym. 2001, 44, 291-303.

20. Yang, L.; Zhang, L.M. Chemical structural and chain conformation characterization of some bioactive polysacchrides isolated from natural source. Carbohydr. Polym. 2009, 76, 349-361.

21. Whistler, R.L.; Wolfrom, M.L. Periodate oxidation: De-termination of periodate, Methods. Carbohydr. Chem. 1962, 1, 435-441.

Sample Availability: Samples of the compounds are not available from the authors.

(C) 2015 by the authors; licensee MDPI, Basel, Switzerland. This article is an open access article distributed under the terms and conditions of the Creative Commons Attribution license (http://creativecommons.org/licenses/by/4.0/). 